\title{
Diasporic experiences portrayed in Luling character as the first-generation in Amy Tan's The Bonesetter's Daughter
}

\author{
1Septiarini Makodamayanti* \\ 1Diyah Fitri Wulandari \\ ${ }^{1}$ English Literature, College of Languages and Communication Science \\ Sultan Agung Islamic University, Semarang, Indonesia
}

*Corresponding Author

Email: makodamaya@std.unissula.ac.id

\begin{abstract}
This study deals with the issue of diaspora which relates to diasporic experiences as well as the impact of diaspora. The research attempted to find out the experiences encountered by LuLing and to know the impact of diaspora perceived by her as the analyzed character, during her process of diaspora. Descriptive Qualitative research was used in the arranging of this undergraduate thesis. The data came from various sources that were classified into primary data and secondary data. The primary data were taken from the Bonesetter's Daughter novel by Amy Tan. The secondary data were taken from book, printed and online journals and articles. The first step for analyzing the data was by reading the whole chapters of the Bonesetter's Daughter novel. While the second step, was underlining or highlighting the parts that showed about the diasporic experiences and the impact of diaspora encountered by LuLing. This study shows how the phenomenon of diaspora invokes some experiences and gives an impact to the diasporas as reflected in the Bonesetter's Daughter novel. The movement of LuLing to America triggered by the war in her country had allowed her to undergo some experiences like acculturation, culture shock, and separation, along with the psychological impact of the movement that she had. Through LuLing, the Chinese first-generation woman character, this novel shows how the Chinese diasporas live their life in a country which is different from their homeland.
\end{abstract}

Keywords: diaspora; diasporic experiences; Chinese's first-generation
Received:
Revised:
Accepted:
Published:
2 October 2018
21 August 2019
27 August 2019
31 August 2019

\section{INTRODUCTION}

Regarded as one of powerful countries, in the past China was not also spared from war, conflict and problem. People flustered, they might lose their home and wealth during the war or conflict, separated from their family, suffered and frightened. Those conditions make people think about a better condition, to be far from problems, safe and secure, which later urge them to leave their country, to move and build a new life in a new country. Conflict, problem, or 
especially the war, makes people long for living in a peace and calm place with the freedom they want to reach for. The picture of country that free from war always passes in their mind. A kind of country like America which regarded as a country that 'free from war' and a country that offers freedom.

For Chinese who are longing for a better living place, they are eager to move to America in order to do diaspora. Brah (1996) stated that what it called as diaspora is when someone is settling down and putting his roots 'elsewhere' and is not just doing a casual travel or a temporary sojourn. The reason why people as Chinese do a diaspora can be based on many things. It can be war and conflict which become the main reason, as what has been experienced by Palestinians, or as African-Carribeans, Asians, Cypriots or Irish who have been induced as part of global flows of labour so that they make a movement (Brah, 1996), otherwise, due to their own desire influenced by their individual reason. However, for any reasons behind why people do a movement or diaspora is that they have the same intention to build a better new life in the future host country.

Nevertheless, moving from their origin country to the new one and living their life there is not as easy as they thought before, especially for the firstgeneration. Like as Papademetriou, Somerville, \& Sumption (2009) state that, "First-generation immigrants are foreign-born persons who have immigrated to the host country and did not have that country's citizenship at birth". Since the host country is a country which has cultural customs and habits, thus the diasporas may undergo some experiences dealing with that issues.

For the first, the diasporas may encounter the process of acculturation. As quoted in Yeh (2003), Berry, LaFromboise, Coleman and Gerton assert, "acculturation refers to the manner in which individuals negotiate two or more cultures. It is assumed that one culture is dominant while the other culture is perceived to have less cultural value". Thus, in the host country the diasporas cope with both, their own culture they bring with and the new culture they just met with. There, the diasporas become a minority group who come into the dominant one where they have to choose either to adjust with it or else, to withdraw from it.

For some diasporas it may easy for them to make a contact with new people in the new society, but there are also a lot of them who get stress to deal with a new circumstance where they later may experience acculturative stress or culture shock. According to Berry as quoted in Kmite (2011), culture shock is another term for acculturative stress. Where based on Oberg (2006), "Culture shock is precipitated by the anxiety that results from losing all our familiar signs and symbols of social intercourse", when the familiar signs such as habits that common to do in everyday life, are removed. Later on, the diasporas may undergo another experience relates to the acculturation process such as assimilation, separation, integration or marginalization that belong to acculturation strategies, which then, it depends on the individual, for he or she, later, will experience which one of these processes.

Since every people is different and so is his or her experiences, it is probable that he or she may be getting through the assimilation. As Berry (1997) states that assimilation strategy is defined, "when individuals do not wish to maintain their cultural identity and seek daily interaction with other cultures", or separation, "when individuals place a value on holding on to their 
original, and at the same time wish to avoid interaction with others". Other than that, he or she may have integration "when there is an interest in both maintaining in one's original culture and in daily interactions with other groups", or, experiencing marginalization, "when there is little possibility or interest in cultural maintenance, and little interest in having relations with others". Thus, the acculturation strategies encountered by the diasporas are the processes that happen and become the part of diasporic experiences.

In doing diaspora and in going through the diasporic experiences, people are experiencing many processes in their life, whether easy or hard, in a brief or in a long period of time, in one or the whole aspect of their life. Change is a thing that possibly happen in the life of diasporas. Even less if it gives a big influence for them at a later time, then the diasporas are facing the impact of diaspora. As Robin Cohen assessed an Afghanistan's immigrant, he stated that from the direct gaze of the man, it can be known that diaspora has both, physical and psychological impact (Cohen, Story, \& Moon, 2005).

The diasporic experiences encountered by the diasporas and the impact appeared after moving to the new country going through the process of diaspora are the same as what is depicted in the Bonesetter's Daughter novel by Amy Tan, when its Chinese woman character named LuLing does a movement or diaspora. Her country, China, which was in a state of war at that time, urged her to find a better place to live. Her acquaintanceship with American women in an orphanage where she was sent by her old family there, later gave her a notion of going to America. Moreover, her belief that America is the Christian heaven where Pan Kain Jing, her first husband who has died goes to, makes her eager to go and move there.

As a Chinese immigrant, she experiences the diasporic experiences started by the process of acculturation, and comes through the process of culture shock which continued by the process of separation. The life she is living through especially after her movement to America gives an impact to her, which is to her psychological aspect. The difficulties she was experienced during her movement to the host countries and during her living in the host countries that lead her to the anxiety, anger, or grief, later bring her to encounter the process of memory which as quoted in Klein (2000), Patrick H. Hutton says, "Memory consists of two moments, repetition and recollection. Repetition involves the "presence of the past", while recollection involves present representations of the past", where she often tells about her past in her origin country, about the cultures and about the things she used to do with Precious Auntie, her biological mother.

Diaspora becomes the topic in this discussion. It deals with the possible diasporic experiences undergone by the diasporas that may be different between one another. Furthermore, it has impacts such as physical and psychological where psychology becomes the impact that is most often experienced by the diasporas. This study will analyze about the diasporic experiences that will be experienced by the diasporas such as Chinese, African, Palestinian, etc. in the host country like America, which are not the same in every individual, along with the impact of diaspora appeared within or after the diasporic experiences as portrayed in the character of LuLing in Amy Tan's the Bonesetter's Daughter. 


\section{RESULTS AND DISCUSSION}

The phenomenon of diaspora deals with people's movement and involves some experiences to the diasporas since they are facing a new circumstance or situation in their life. There are many experiences that are possibly encountered by the diasporas like Chinese. They may undergo acculturation, culture shock, or one of the acculturation strategies like assimilation, separation, etc. However, not all of them will encounter similar and in sequence experiences. They may have different experiences between one and others that those are influenced by several factors such as age, education, mental and physical health, and so on. Other than that, the process of dispersion in diaspora which involves two or more countries is kind of a process which is not quite easy to pass. The movement may bring an impact to the diasporas that can be physical or psychological. Thus, for the people who get on the psychological impact in the form of anxiety, grief, stress, or depression, these may lead the diasporas to undergo the process of memory. From a novel entitled the Bonesetter's Daughter by Amy Tan as the object of this study, the phenomenon of diaspora along with diasporic experiences and the impact of diaspora encountered by the character named LuLing, will be discussed on further.

\section{The Process of Diaspora as Reflected in the Novel}

Amy Tan's the Bonesetters's Daughter whose character is a Chinese woman named LuLing, tells about LuLing's life in several countries. The issue deals with the phenomenon of diaspora where the movement is affected by either forced or unforced factors. The forced factor can be triggered by war or conflict in their country, as Brah (1996) states:

... Perhaps the dispersion occurred as a result of conflict and war, resulting in the creation of a nation state on the territory previously occupied by another, as has been the experience of Palestinians since the formation of Israel . . . .

The news about the coming of Japanese that was aired through a radio which was retold by Pan Kai Jing later known by LuLing that it was also became the news of the war in her land, "When Kai Jing finally told me, I didn't have even one moment to be relieved that the bad news was not about me. 'The Japanese attacked last night, he said, 'close to Peking, and everyone is saying it is war for sure." (Tan, 2001). Thus, the war in her land, China, became the forced factor for LuLing moved to another country.

While the unforced factor can be based on personal reason as owned by LuLing. Her belief about America that dealt with the death of Pan Kai Jing had given a notion for her to move to America, "In my heart, America was the Christian heaven. It was where Kai Jing had gone, where he was waiting for me." (Tan, 2001). One of the essential things of diaspora that is about putting roots 'elsewhere' may let the diasporas to reside in another place for any kind of reasons including personal reason. As stated by Brah (1996), "Diasporas are clearly not the same as casual travel. Nor do they normatively refer to 
temporary sojourns. Paradoxically, diasporic journeys are essentially about settling down, about putting roots 'elsewhere"'.

For the destination country, America becomes the most destined country for the diasporas. There are several reasons for them to go there. Besides considered as a country that can offer freedom, the diasporas as Chinese regard America as the place where they can build a better life there. As quoted in Takyi \& Konadu-Agyemang (2006), Jones conveyed that as the destination country, America offers great economy opportunities besides its readiness for assimilation and social mobility in its social and political institutions. This is also realized by LuLing when an offer of going to America from Miss Grutoff, the headmaster who is an American, came up to the orphanage people:

America? Miss Grutoff did not ask this only as a favor. We all knew she was also offering a great opportunity. A visa to America . . . In my heart, America was the Christian heaven. It was where Kai Jing had gone, where he was waiting for me. I knew this was not actually true, but there was a hope that I could find happiness that stayed hidden from me. I could leave the old curse, my bad background. (Tan, 2001).

A presumption that America was a big land that could give a great opportunity to everyone who came there also passed within the thought of the orphanage people including LuLing and GaoLing. GaoLing was LuLing's sister from the family she ever lived with, who was also living in the orphanage along with LuLing. That was why, besides LuLing who wanted to go there, GaoLing also wanted to be the one who could accompany Miss Grutoff back to America.

In other hand, as quoted in Butler (2001), William Safran stated that diaspora has several characteristics which one of those is dispersal to two or more locations. Before finally moved to America, LuLing prior lived in Hong Kong:

Each night when I returned to the rooming house in Hong Kong, I lay on a cot with wet towels over my chest. . . . I was living in Kowloon Walled City, along the low point in a wide gutter, when the scales and blood and guts gathered, swept there by the fishmongers' buckets of water at night. . . (Tan, 2001).

The reason LuLing lived in Hong Kong was because she wanted to wait a sponsor from GaoLing, since she became the one who finally accompanied Miss Grutoff to America. LuLing needed GaoLing's sponsor to be able to move to America. After several months lived there, LuLing finally went to America as a Famous Visiting Artist:

The next day, I sold the oracle bone to the second shop I had gone to all those months ago. With my savings as a maid, I had enough money to buy a ticket in steerage. I got the boat schedule and sent GaoLing a telegram. Every few days, I gave Fu Nan money for his habit, enough to put him into dreams. And then finally the visa was approved. I was a Famous Visiting Artist.

I sailed for America, a land without curses or ghosts. By the time I landed, I was five years younger. Yet I felt so old. (Tan, 2001). 
That was a sponsor GaoLing got from an American citizen. In America, GaoLing who apparently kept trying to search a sponsor for LuLing, met two brothers whose family name was Young. The father of the family was the one who raised the notion about Famous Visiting Artist sponsor. Though she needed to make a few changes to her data dealing with her year of birth, but at last she could go there when she was thirties.

As a Chinese woman who moved to America when she was adult, LuLing then belonged to the group of first-generation people. According to Papademetriou et al. (2009), "First-generation immigrants are foreign-born persons who have immigrated to the host country and did not have that country's citizenship at birth". Thus, LuLing was born and raised in China, "I was raised with the Liu clan in the rocky Western Hills south of Peking . . ." (Tan, 2001), and did not have the America's citizenship at birth.

\section{Diasporic Experiences as Reflected in the Novel}

During her live in Hong Kong before she went to America, LuLing encountered some diasporic experiences. For first, she underwent the process of acculturation where she negotiated to two cultures which were her own culture and the culture of Hong Kong and the people. Barely though, she tended to follow the culture of Hong Kong's people, “. . . I realized that in Hong Kong, I had come to a place where everyone believed he could change his situation, his fate, no more staying stuck with your circumstances. And there were many ways to change ..." (Tan, 2001). Accordingly, as quoted in Yeh (2003), Berry, LaFromboise, Coleman and Gerton state that, "acculturation refers to the manner in which individuals negotiate two or more cultures. It is assumed that one culture is dominant while the other culture is perceived to have less cultural value". LuLing's movement to Hong Kong in order to wait a sponsor from GaoLing forced her to stay there in uncertain time. To bear her life during the waiting time, there she needed to find a living place and a job as well. LuLing who prior felt pessimistic about whether or not she could bear life in Hong Kong then tried change her mind to be more positive. She tried to be as Hong Kong people who always believed that they could make their life better.

While in America, LuLing encountered the process of acculturation that dealt with language where it could implicitly be caught from Ruth's memory about her mother, "And since immigrating to the United States fifty years before, she had not improved either her pronunciation or her vocabulary." (Tan, 2001). That was Ruth, LuLing's daughter, who once examining her mother's demeanor, about why she was easy to be angry and offended, found that those were apparently dealt with the language ability. Her mother's language ability that was not as good as her aunt, had already existed even since the first time her mother moved to America. From Ruth story, it seemed like she was intending to say that her mother had a poor English. But actually, Ruth had indirectly showed the acculturation process had been undergone by LuLing. That was about LuLing who negotiated with the culture of America by using English as her language instead of speaking in her own language. Unfortunately, LuLing was not fully succeed in encountering her acculturation process when she lived in America. It because she never got her English to be better even after decades living in that country. Though so, it 
still could be known that LuLing had tried to negotiate with the culture of America. As living in the country which had the more dominant culture where the people were speaking in English, LuLing who used to speak in Chinese tried to follow the culture of America by speaking English in accordance with her ability.

Other than encountering acculturation, LuLing also experiencing culture shock. The experience comes from psychological changes of the diasporas, as John W. Berry (2005) stated that psychological changes on individual level can be the changes that either, easily to overcome called behavioral shifts such as the way of speaking, dressing, or eating, or the problematic one that leads to acculturative stress such as anxiety and depression. As the following step of acculturation, culture shock happens when the diasporas cannot easily handle the problems that arise during the process of acculturation moreover those which dealt with psychological changes. They usually face difficulties affected by culture differences that may be able to lead them feeling worry with their life or getting stress with the situation they are facing. In addition, Oberg (2006) states, "culture shock is precipitated by the anxiety that results from losing all our familiar signs and symbols of social intercourse". The experience of losing familiar sign also happened to LuLing when she worked with British ladies in Hong Kong:

When I first went to live there, she spoke to me in the local talk, which I could not understand except for the words that sounded a little like Mandarin. Later she mixed in a bit of English, some of which I knew from living at the orphanage school. But Miss Patsy spoke English like a British person, and at first it was very hard for me to understand. (Tan, 2001)

Speaking Mandarin and knowing a bit about English from the American missionaries when she lived in the orphanage, in Hong Kong LuLing got a British employer who spoke English and Cantonese. Though Cantonese sometimes almost similar like Mandarin and though she might catch some English words spoken by her employer, but LuLing still found difficulty because she was not fluent in either English or Cantonese. Moreover when her employer spoke in English with her British accent which was unpredictably hard to be understood, that was the time she got a feeling of hardship dealing with the matter of communication with others. There, LuLing who used to communicate in Mandarin faced an anxiety for not being able to understand the utterances spoken by her employer. Thus the difference of the language became the reason of LuLing's anxiety which also as the sign that she was undergoing culture shock.

Whereas in America, LuLing who had poor English encountered one of the symptoms of culture shock which was defensiveness, "But the way Ruth saw it, LuLing got into fights mainly because of her poor English. She didn't understand others, or they didn't understand her." (Tan, 2001). As quoted in Liu, Volcic, \& Gallois (2014), Adler states that:

culture shock involves both, psychological and social process which evolves through several stages. For some people, it can be either needs a brief moment or takes a long time to overcome the social and especially the psychological process of culture shock whose 
symptoms are depression, helplessness, anxiety, homesickness, confusion, irritability, isolation, intolerance, defensiveness, etc.

Thus, as a language she used in the previous social intercourse, Chinese language seemed to be LuLing's tool in conveying her thought, feeling, or emotion. However, moved to the country where the people were all speaking in English, LuLing who had a poor English seemed did not find a way to clearly convey her feelings. At last, to keep her opinions be heard in the midst of her poor English, LuLing turned to be a stiff and defensive woman.

Besides, in America LuLing also encountered one of the acculturation strategies which was separation. Based on J W Berry (1997), separation is "when individuals place a value on holding on to their original, and at the same time wish to avoid interaction with others". LuLing's poor English also made her avoid interaction with other people:

'You shouldn't let them eat those things!' LuLing scolded, continuing in Mandarin. 'Tell them you don't allow this anymore.'

'Girls, I wish you wouldn't ruin your appetites with junk food.'

'And I wish you two would stop talking like spies in Chinese,' Fia said. 'It's like really rude.'

...'Waipo speaks Chinese,' Ruth said, 'because that's the language she's used to.'...

'She can speak English too,' Dory said (Tan, 2001).

That was when LuLing had a dinner with Ruth and the daughter of Ruth's boyfriend named Fia and Dory. Instead of talking directly to the girls for not eating junk food, LuLing was preferred to talk to Ruth in Chinese. Thus, the act LuLing did in front of the girls showed the separation strategy when she kept her culture by talking Mandarin and avoided a direct interaction with both of them.

\section{The Impact of Diaspora as Reflected in the Novel}

Robin Cohen who assessed an Afghanistan's immigrant stated that from the direct gaze of the man, it can be known that diaspora has both, physical and psychological impact (Cohen et al., 2005). The background of LuLing's movement and the difficulties that she faced in the host countries gave a psychological impact to her. That was then she encountered the process of memory that based on Patrick H. Hutton, as quoted in (Klein, 2000), he says, "Memory consists of two moments, repetition and recollection. Repetition involves the "presence of the past", while recollection involves present representations of the past". The recollection moment that involved present representations of the past was undergone by LuLing when she tried to teach Ruth to write Chinese letter:

'Bao Bomu taught me how to write,' LuLing said one evening. 'She taught me how to think. When you write, she said, you must gather free-flowing of your heart.' To demonstrate, LuLing wrote the character for 'heart.' 'See? Each stroke has its own rhythm, its balance, its proper place. Bao Bomu said everything in life should be the same way.'

'Who's Bao Bomu again?' Ruth asked. (Tan, 2001) 
What was taught to Ruth showed or reflected about LuLing's past moment with Precious Auntie when she taught LuLing to write Chinese letter. While the repetition moment that involved the 'presence of the past' happened when she frequently felt the coming of the 'ghost' of Precious Auntie in her present life:

. . . But then her mother began to whimper, 'Doggie, doggie,' in Chinese. She jumped up and her chest heaved. 'Precious Auntie,' LuLing cried, 'you've come back. This is your Doggie. Do you forgive me?'

Ruth put down the chopstick.

LuLing was now sobbing. 'Precious Auntie, oh Precious Auntie! I wish you never died! It was all my fault. If I could change fate, I would rather kill myself than suffer without you ...'

Oh, no. Ruth knew what this was. Her mother sometimes talked about this Precious Auntie ghost who lived in the air. . . (Tan, 2001)

The death of Precious Auntie preceded by fray between her and LuLing, living a big regret to LuLing that she could not forget it and always felt guilty every time she remembered it. Doggie, a nickname Precious Auntie gave to her which mentioned by Ruth made her remembered about her fray with Precious Auntie in the past. Thus, LuLing suddenly cried and felt the coming of the 'ghost' of Precous Auntie near to her.

\section{CONCLUSION}

This study aims to show the diasporic experiences of LuLing, as a firstgeneration Chinese woman, along with the impact of diaspora perceived by her. Those cases happen as part of the phenomenon of diaspora that has been prior encountered by her. Through her work, Amy Tan tries to depict the life of Chinese woman who leaves her land, China, and moves to two host countries of Hong Kong and America. In the Bonesetter's Daughter novel, all the diasporic experiences undergone by LuLing and the psychological impact encountered by her can be found from the chapters in the book.

From the data findings which have been analyzed, some conclusions are collected. The Bonesetter's Daughter novel shows about diasporic experiences undergone by LuLing that include the process of acculturation, acculturative stress or culture shock, and one of acculturation strategies which is separation. During her live in two host countries which are in Hong Kong and in America, LuLing has encountered both acculturation and culture shock. The experiences of acculturation are showed when LuLing negotiates with the culture of Hong Kong's people, her British employer, and American people. While the experiences of culture shock are showed when she faces some difficulties dealing with language with her employer in Hong Kong and the American. Whereas only in America as the last destination country, LuLing has encountered separation when she prefers to maintain her culture instead of mingling with people in the new society.

Besides the diasporic experiences, the impact of the phenomenon of diaspora is also encountered by LuLing. She undergoes the psychological impact which leads her to run into the process of memory. The process consists of two moments which are repetition and recollection. The repetition 
moments that involve 'the presence of the past' happen when LuLing frequently feels the existence of the 'ghost' of Precious Auntie. While the recollection moments that involve present representation of the past happen when LuLing tries to do things she used to do in the past. Thus, the two moments happen to LuLing are mostly have a relation with Precious Auntie, the woman who actually is her biological mother.

\section{REFERENCES}

Berry, J W. (1997). Lead Article: Immigration, Acculturation, and Adaption. Applied Psychology: An International Review, 46(1), 5-68. https://doi.org/10.1111/j.1464-0597.1997.tb01087.x

Berry, John W. (2005). Acculturation: Living successfully in two cultures. International Journal of Intercultural Relations, 29 (6 SPEC. ISS.), 697712. https://doi.org/10.1016/j.ijintrel.2005.07.013

Brah, A. (1996). Thinking Through the Concept of Diaspora. In Cartographies of Diaspora: Contesting Identities (pp. 443-446). London \& New York: Routledge.

Butler, K. D. (2001). Defining-Diaspora, Refining a Discourse. Diaspora, 10(2), 189-219.

Cohen, R., Story, J., \& Moon, N. (2005). The Impact of Diasporas on the Making of Britain: Evidence, Memories, Inventions. Oxford: Oxford Diasporas Programme.

Klein, K. L. (2000). On the Emergence of Memory in Historical Discourse. JSTOR, 127-150.

Kmite, L. (2011). Acculturation and adaptation among Lithuanian workers in Norway. University of Stravanger.

Liu, S., Volcic, Z., \& Gallois, C. (2014). Introducing Intercultural Communication: Global Cultures and Contexts. SAGE, 199-222.

Oberg, K. (2006). Cultural Shock: Adjustment to New Cultural Environments, 29, 142-146.

Papademetriou, D. G., Somerville, W., \& Sumption, M. (2009). The Social Mobility of Immigrants and Their Children. MPI Transatlantic Council on Migration, (June), 1-22. Retrieved from http://www.migrationpolicy.org/pubs/soialmobility2010.pdf

Takyi, B. K., \& Konadu-Agyemang, K. (2006). Theoritican Perspectives on African Migration. In The New African Diaspora in North America: Trends, Community Building, and Adaptation (pp. 13-27). United State: Lexington Books.

Tan, A. (2001). The Bonesetter's Daughter. London: Flamingo.

Yeh, C. J. (2003). Age, Acculturation, Cultural Adjustment, and Mental Health Symptoms of Chinese, Korean, and Japanese Immigrant Youths, 9(1), 34-48. https://doi.org/10.1037/1099-9809.9.1.34 